\title{
A Short-Term Electricity Price Forecasting Scheme for Power Market
}

\author{
Gao Gao, Kwoklun Lo, Jianfeng Lu, Fulin Fan \\ Department of Electronic and Electrical Engineering, University of Strathclyde, Glasgow, UK \\ Email: gao.gao@strath.ac.uk
}

How to cite this paper: Gao, G., Lo, K., Lu, J.F. and Fan, F.L. (2016) A Short-Term Electricity Price Forecasting Scheme for Power Market. World Journal of Engineering and Technology, 4, 58-65.

http://dx.doi.org/10.4236/wjet.2016.43D008

Received: July 6, 2016

Accepted: October 13, 2016

Published: October 20, 2016

\begin{abstract}
Electricity price forecasting has become an important aspect of promoting competition and safeguarding the interests of participants in electricity market. As market participants, both producers and consumers intent to contribute more efforts on developing appropriate price forecasting scheme to maximize their profits. This paper introduces a time series method developed by Box-Jenkins that applies autoregressive integrated moving average (ARIMA) model to address a best-fitted time-domain model based on a time series of historical price data. Using the model's parameters determined from the stationarized time series of prices, the price forecasts in UK electricity market for 1 step ahead are estimated in the next day and the next week. The most suitable models are selected for them separately after comparing their prediction outcomes. The data of historical prices are obtained from UK three-month Reference Price Data from April $1^{\text {st }}$ to July $7^{\text {th }} 2010$.
\end{abstract}

\section{Keywords}

Box-Jenkins Method, ARIMA Models, Electricity Markets, Electricity Prices, Forecasting

\section{Introduction}

Worldwide electricity market reform makes the power industry transform from gradually monopoly to competition. As market participants, each supplier and consumer wants to get the most benefits [1]. If the electricity price can be predicted accurately, generation side could handle the market dynamic and make optimal power generation plan. Demand side could select their time of power use and choose the electric quantity they want to buy for reducing the cost and increasing market competitiveness [2]. For regulators, grid reference price forecast results can help to improve the monitoring capability of electricity market operation and discover and resolve the problems in the 
market. Also, government can formulate related policies by electricity prices and guide electricity market development [3].

Many electricity price forecasting methods have been proposed, and they generally can be divided into market simulation and the method centred on history data. Market simulation predicts the market clearing prices by simulating the competition operation. The second kind of method based on time series analysis of history data to build mathematical model and make the prices forecasting [4]. Box-Jenkins method belongs to the time-series model. Box-Jenkins Analysis refers to a systematic method of identifying, fitting, checking, and using autoregressive integrated moving average (ARIMA) time series models.

In the late 1980s, UK took the lead in implementing industry privatization reform and proposed deregulation of the electricity power supply industry. The deregulated Scottish electricity market was formed in 1998 and the whole of the UK market was formed two years later. All customers in the market can choose their power suppliers freely [5]. On 27 March 2001, the market introduced new market mechanisms and trading patterns in England and Wales, the New Electricity Trading Arrangements (NETA) and was later extended to cover the whole of the UK (BETTA) [6].

\section{Box-Jenkins Methodology}

\subsection{Autoregressive Integrated Moving Average (ARIMA) Models}

ARIMA model is a time-series forecasting method which was proposed by Box and Jenkins in the early 1970s [7].ARIMA model contains three factors, $p, d$ and q. AR is autoregressive (p), MA is moving average ( $q$ ) and $\mathrm{d}$ is the level of differencing to stationarize the time series. The formula of the ARIMA model is:

$$
\phi(B)(1-B)^{d} z_{t}=\theta_{0}+\theta(B) a_{t}
$$

where $\phi(B)$ is the operator of $\mathrm{p}$ and $\theta(B)$ is the operator of $\mathrm{q}$. Their zeros need to be outside the unit circle. $B$ is the lag operator, $z_{t}$ is the historical data at time $t$ and $\theta_{0}$ is the constant term. The error term $a_{t}$ is generally assumed to be independent and its average value is zero [8].

Electricity prices are highly non-stationary time series of strong volatility and periodicity. A time series based forecasting model is usually carried out for the analysis and prediction of stationary series. Therefore, it is necessary to transfer the electricity price to a stationary time series, which is termed the pre-treatment process. Differencing is the major approach to convert time series form non-stationarity to stationarity. Provided the electricity price series are $z_{t}, \nabla z_{t}$ is the first order difference of $z_{t}, \nabla^{d} z_{t}$ is the $\mathrm{d}^{\text {th }}$ order difference of $z_{t}$ :

$$
\begin{aligned}
& \nabla z_{t}=z_{t}-z_{t-1} \\
& \nabla^{d} z_{t}=\nabla^{d-1} z_{t}-\nabla^{d-1} z_{t-1}
\end{aligned}
$$

Usually when the value of $d$ is up to 2 , the differenced time series could become stationary. There are a number of methods to detect the stationarity of the differenced 
time series [9]. In this paper, the model's residuals are used to verify the goodness of fit. The modelling process can then be carried out.

Using the stationsrized time series, the ARIMA process may be simplified to the mixed autoregressive moving average (ARMA) process:

$$
\phi(B) \omega_{t}=\theta_{0}+\theta(B) a_{t}
$$

where

$$
\omega_{t}=(1-B)^{d} z_{t}=\nabla^{d} z_{t}
$$

It also can be expressed as:

$$
\tilde{z}_{t}=\phi_{0}+\phi_{1} \tilde{z}_{t-1}+\phi_{2} \tilde{z}_{t-2}+\ldots+\phi_{p} \tilde{z}_{t-p}+a_{t}+\theta_{1} a_{t-1}+\theta_{2} a_{t-2}+\ldots+\theta_{q} a_{t-q}
$$

The autoregressive (AR) part is a linear combination of the past $\mathrm{p}$ observations $\tilde{z}_{t-1} \ldots \tilde{z}_{t-p}$, weighted by plinear coefficients $\phi_{1} \ldots \phi_{p}$ and a constant term $\phi_{0}$. The moving average (MA) part is a linear combination of the past q linear coefficients $a_{t-1} \ldots a_{t-q}$, weighted by q linear coefficients $\theta_{1} \ldots \theta_{q}$, and the current noise term $a_{t}$. Based on the central limit theorem, the noise terms $a_{t}$ are normally distributed with mean zero and constant variance $\sigma^{2}[10]$.

The main tool used to identify the resulting ARMA model is the sample autocorrelation function (ACF) and the sample partial autocorrelation function (PACF). Table 1 summarizes standard patterns and provides guidelines for determining the integers $\mathrm{p}$ and $\mathrm{q}$, identifying the most influential $\mathrm{p}$ observations and $\mathrm{q}$ noise terms in an ARMA (p, q) model [11].

\subsection{Autocorrelations and Partial Autocorrelations Models}

Autocorrelations (AC) reflect the linear dependencies among every sequential value $\tilde{z}_{t}, \tilde{z}_{t-1}, \ldots, \tilde{z}_{t-k}$, in the electricity price sequence. $\tilde{z}_{t}$ and $\tilde{z}_{t+k}$, separated by time lags $\mathrm{k}$ $=1,2, \ldots$.The autocorrelation coefficient $r_{k}$ at lag $\mathrm{k}$ figures out the average variation associated with the sample mean $\hat{z}$ normalized by the sample variance $\hat{\sigma}^{2}$, of all pairs separated by $\mathrm{k}$ lags. Hence, $r_{k}$ at lag $\mathrm{k}$ of the electricity price series of size $\mathrm{N}$ is:

$$
\begin{aligned}
& r_{k}=\frac{\sum_{t=1}^{N-k}\left(\tilde{z}_{t}-\hat{z}\right)\left(\tilde{z}_{t+k}-\hat{z}\right)}{N \cdot \hat{\sigma}^{2}} \\
& \hat{\sigma}^{2}=\frac{1}{N} \sum_{t=1}^{N}\left(\tilde{z}_{t}-\hat{z}\right)^{2}
\end{aligned}
$$

The range of autocorrelation coefficient $r_{k}$ is $[-1,1]$ and the magnitude $\left|r_{k}\right|$ represents the intensity of dependency. The more $\left|r_{k}\right|$ is close to 1 , the higher correlation intensity of the series.

Table 1. Standard patterns in the theoretical ACFs and PACFs of stationary series.

\begin{tabular}{ccc}
\hline Model & ACF & PACF \\
\hline AR(p) & exponential or sinusoidal decay to zero & spikes cut off to zero after lag p \\
MA(q) & spikes cut off to zero after lag $\mathrm{q}$ & exponential or sinusoidal decay to zero \\
ARMA $(\mathrm{p}, \mathrm{q})$ & exponential or sinusoidal & exponential or sinusoidal \\
& decay to zero after lag $\mathrm{q}$ & decay to zero after lag $\mathrm{p}$ \\
\hline
\end{tabular}


For the price time series $\tilde{z}_{t}$, under the given situation $\tilde{z}_{t-1}, \tilde{z}_{t-2}, \ldots, \tilde{z}_{t-k+1}$, the partial autocorrelation (PAC) measures the degree of association between two random variables $\tilde{z}_{t}$ and $\tilde{z}_{t-k}$. The partial autocorrelation $\varphi_{k k}$ of the price time series $\tilde{z}_{t}$ is

$$
\varphi_{k k}= \begin{cases}r_{1} & k=1 \\ \frac{r_{k}-\sum_{j=1}^{k-1} \varphi_{k-1, j} r_{k-j}}{1-\sum_{j=1}^{k-1} \varphi_{k-1, j} r_{j}} & k>1\end{cases}
$$

where $r_{k}$ is the autocorrelation coefficient of price series at lag $\mathrm{k}$.

$$
\varphi_{k, j}=\varphi_{k-1, j}-\varphi_{k k} \varphi_{k-1, k-j} \quad j=1,2, \ldots, k-1
$$

The range of partial autocorrelation coefficient $\varphi_{k k}$ is also $[-1,1]$. In practical applications, it is necessary to consider both autocorrelations and partial autocorrelations of the time series [12].

\subsection{The Procedure of ARIMA Modelling}

The half-hourly updated UK Reference Price Data (RPD) over 91 days from April $1^{\text {st }}$ to June $30^{\text {th }}$ 2010were obtained from Power Spot Exchange (www.apxgroup.com). The objective is to predict the 1-step-ahead price forecast in the next day (July $1^{\text {st }}$ ) and next week (from July $1^{\text {st }}$ to $7^{\text {th }}$ ).

There are five steps to complete the ARIMA modelling:

1. Stationarize the time series.

2. Identify the model based on the observed data.

3. Determine the parameters of the model.

4. Check the goodness of fit.

5. Use the tested model to do the forecasting [13].

\section{Results and Discussion}

The parameters of the ARIMA models are determined from the historical price data over three months (April, May and June 2010). The price forecasts for 1 step ahead in the next day on July $1^{\text {st }}$ produced by the $\operatorname{ARIMA}(1,1,1)$ and the next week from July $1^{\text {st }}$ to July $7^{\text {th }}$ produced by the $\operatorname{ARIMA}(1,1,1)$ are compared with their actual price values as shown in Figure 1 and Figure 2 respectively. The dashed lines representing the actual values and the solid lines representing the forecasts are well covered by each other which indicate good forecasting performances are achieved in both figures.

Mean absolute error (MAE) and root-mean-square error (RMSE) [14] are used to characterise the differences between predicted values and observed values. The formulas are given by:

$$
R M S E=\sqrt{\frac{\sum_{t=1}^{n}\left(f_{t}-y_{t}\right)^{2}}{n}} \quad M A E=\frac{1}{n} \sum_{t=1}^{n}\left|f_{t}-y_{t}\right|
$$

where $f_{t}$ is the predicted value, $y_{t}$ is the observed value and $\mathrm{n}$ is the number of testing samples. The MAEs and RMSEs of price forecasts in the next day and the next week produced by different ARIMA models are shown in Table 2 and Table 3 respectively. 
Table 2. MAEs and RMSEs of 1-step-ahead price forecasts for different ARIMA models on July 1 st 2010.

\begin{tabular}{ccccccc}
\hline Model & $0,1,1$ & $1,1,0$ & $1,1,1$ & $1,1,2$ & $2,1,1$ & $2,1,2$ \\
\hline MAE & 1.7991 & 1.7969 & 1.7575 & 1.7677 & 1.7635 & 1.7879 \\
RMSE & 2.2967 & 2.2961 & 2.2647 & 2.2716 & 2.2696 & 2.2796 \\
\hline
\end{tabular}

Table 3. MAEs and RMSEs of 1-step-ahead price forecasts for different ARIMA models from July 1 st to July 7 th 2010.

\begin{tabular}{ccccccc}
\hline Model & $0,1,1$ & $1,1,0$ & $1,1,1$ & $1,1,2$ & $2,1,1$ & $2,1,2$ \\
\hline MAE & 2.0403 & 2.0449 & 2.0398 & 2.0419 & 2.0412 & 2.0424 \\
RMSE & 2.5599 & 2.5714 & 2.5591 & 2.5660 & 2.5661 & 2.5636 \\
\hline
\end{tabular}

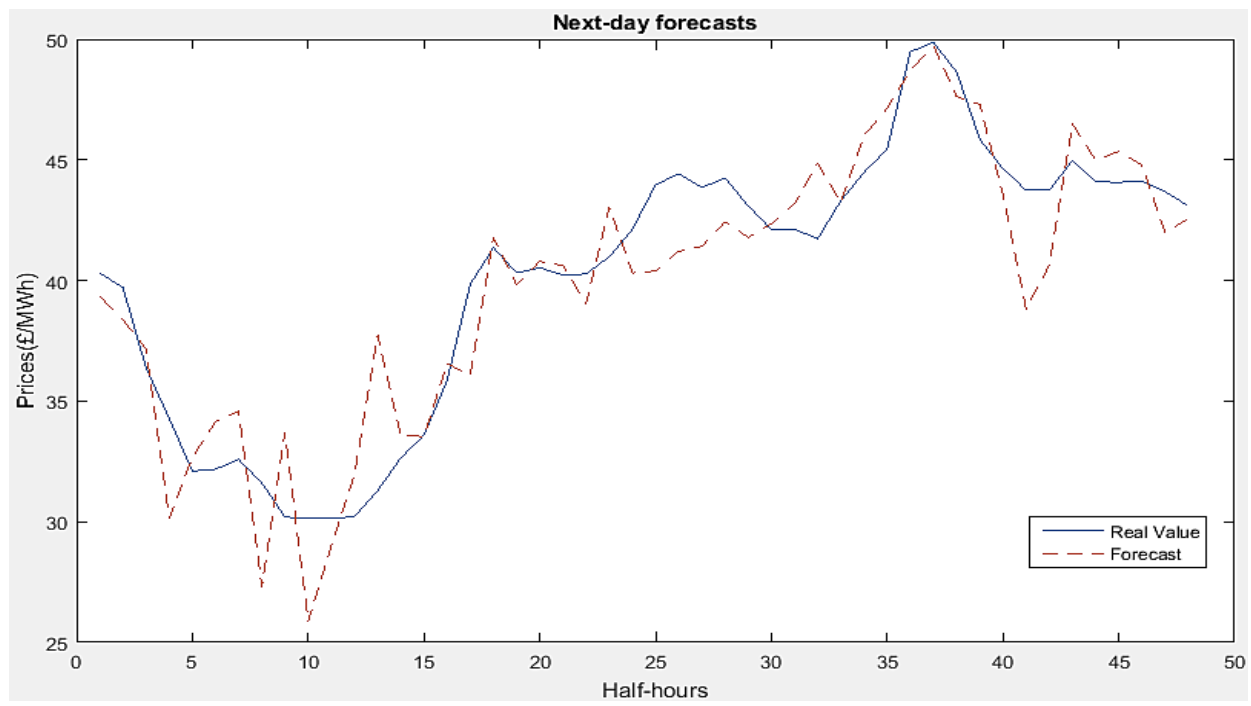

Figure 1. Price forecasts for 1 step ahead produced by the ARIMA $(1,1,1)$ model on July 1 st 2010.

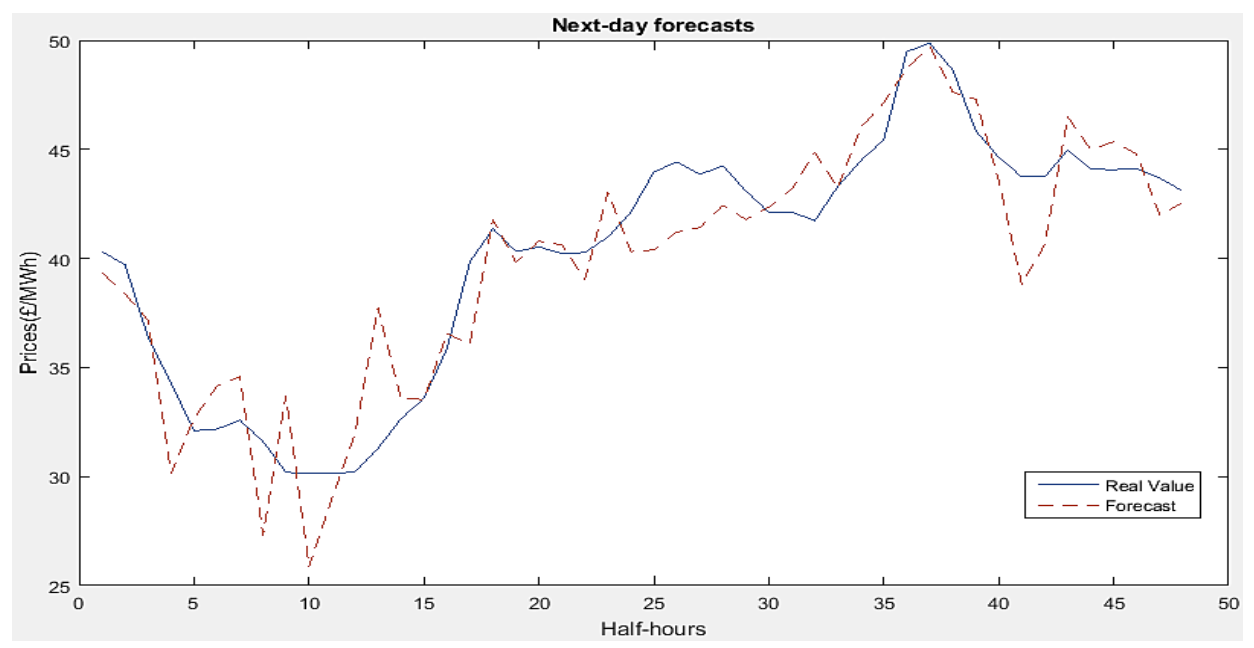

Figure 2. Price forecasts for 1 step ahead produced by the ARIMA $(1,1,1)$ model from July 1 st to July 7 th 2010 . 
The ARIMA $(1,1,1)$ model are generally shown to generate the 1-step-ahead price forecasts of the minimum MAEs and RMSEs in Table 2 and Table 3 . In order to check the quality of the forecasting model, the MAEs and RMSEs of ARIMA $(1,1,1)$ model are compared with the ones given by persistence forecasting. Persistence forecasting (PF) is the simplest form of short-term forecasting which assumes the forecast value $v_{f}(t+T)$ at $\mathrm{T}$ time ahead equal to the current value $v_{f}(t)$ [15]. The persistence forecast error is used here as a benchmark for the ARIMA $(1,1,1)$ model.

Table 4 compares the MAEs and RMSEs of 1-step-ahead and 3-steps-ahead forecasts on July $1^{\text {st }} 2010$ and during the week from July $1^{\text {st }}$ to July $7^{\text {th }} 2010$ for the ARIMA $(1,1,1)$ model and persistence forecasting.

It can be observed that both MAEs and RMSEs of the ARIMA $(1,1,1)$ model are smaller than PF. Especially for the price forecasts during the week, the MAE and RMSE of $\mathrm{PF}$ reached 4.58 and 6.50 respectively, which are much bigger than that of the ARIMA $(1,1,1)$ model.

\section{Conclusions and Future Work}

This paper has proposed an ARIMA model for the1-step-ahead electricity price forecasting based on historical price data in UK electricity market. Depending on the forecast accuracy in terms of MAE and RMSE, an appropriate forecasting model has been selected. Every component of the modelling process could affect the forecasts. Furthermore, to raise the accuracy of forecasting results, increasing the historical data and making short-time prediction are effective. But if the historical data is increased beyond a certain quantity, the accuracy will increase very slowly after a certain value.

The selected ARIMA $(1,1,1)$ model is shown to have a reasonably satisfactory forecasting performance. The errors of persistence forecasts are additionally estimated as a benchmark over which the ARIMA $(1,1,1)$ model gives a significant improvement in both MAE and RMSE.

Future work will continue to refine the optimal models for predicting electricity price and build a rolling forecasting process in electricity market to achieve more accurate results step-by-step. Alternatively, other statistical models, e.g., an artificial neural network (ANN) model or an AR model combined with trend modelling [16] will be established and their forecast accuracies will be compared with the ARIMA models. The optimum models will be employed to generate the electricity price forecasts of high reliability and accuracy.

Table 4. MAEs and RMSEs of 1-step-ahead price forecasts for the ARIMA $(1,1,1)$ model and persistence forecasting.

\begin{tabular}{ccccc}
\hline \multirow{2}{*}{ Model } & \multicolumn{2}{c}{ Day ahead forecasting } & \multicolumn{2}{c}{ Week ahead forecasting } \\
\cline { 2 - 5 } & ARIMA $(1,1,1)$ & PF & ARIMA $(1,1,1)$ & PF \\
\hline \multirow{2}{*}{ MAE } & 1.7575 & 2.9547 & 2.0398 & 4.5849 \\
RMSE & 2.2647 & 3.8969 & 2.5591 & 6.5039 \\
\hline
\end{tabular}




\section{Acknowledgements}

The authors would like to thank Power Spot Exchange for supplying UK historical electricity prices.

\section{References}

[1] von der Fehr, N.-H.M. and Harbord, D. (1993) Spot Market Competition in the UK Electricity Industry. The Economic Journal, 103, 531-546.

[2] Nicolaisen, J. and Petro, V. (2001) Tesfatsion. Market Power and Efficiency in a Computational Electricity Market with Discriminatory Double-Auction Pricing. IEEE Transactions on Evolutionary Computation, 5.

[3] Saini, A. and Saxena, A.K. (2010) Optimal Power Flow Based Congestion Management Methods for Competitive Electricity Markets. International Journal of Computer and Electrical Engineering, 2, 1793-8163. http://dx.doi.org/10.7763/ijcee.2010.v2.116

[4] Li, G. (2007) Day-Ahead Electricity Price Forecasting in a Grid Environment. IEEE Transactions on Power Systems, 22.

[5] Giuliettia, M., Grossib, L. and Waterson, M. (2010) Price Transmission in the UK Electricity Market: Was NETA Beneficial? Energy Economics, 32, 1165-1174. http://dx.doi.org/10.1016/j.eneco.2010.01.008

[6] Lo, K.L. and Wu, Y.K. (2003) Risk Assessment Due to Local Demand Forecast Uncertainty in the Competitive Supply Industry. IEE Proc.-Gener. Transm. Distrib., 150.

http://dx.doi.org/10.1049/ip-gtd:20030641

[7] Naylor, T.H., Seaks, T.G. and Wichern, D.W. (1972) Box-Jenkins Methods: An Alternative to Econometric Models. International Statistical Review/Revue Internationale de Statistique, 40, 123-137.

[8] Box, G.E.P., Jenkins, G.M. and Reinsel, G.C. (2008) Time Series Analysis: Forecasting and Control. 4th Edition, Wiley, Oxford. http://dx.doi.org/10.1002/9781118619193

[9] Nogales, F.J., Contreras, J., Conejo, A.J. and Espínola, R. (2002) Forecasting Next-Day Electricity Prices by Time Series Models. IEEE Trans. Power Syst., 17, 342-348. http://dx.doi.org/10.1109/TPWRS.2002.1007902

[10] Hoa, S.L., Xieb, M. and Gohb, T.N. (2002) A Comparative Study of Neural Network and Box-Jenkins ARIMA Modeling in Time Series Prediction. Computers \& Industrial Engineering, 42, 371-375. http://dx.doi.org/10.1016/S0360-8352(02)00036-0

[11] Aggarwal, S.K., Saini, L.M. and Kumar, A. (2009) International Journal of Electrical Power \& Energy Systems. Electrical Power and Energy Systems, 31, 13-22. http://dx.doi.org/10.1016/j.ijepes.2008.09.003

[12] Tran, N. and Reed, D.A. (2004) Automatic ARIMA Time Series Modeling for Adaptive I/O Prefetching. IEEE Transactions on Parallel and Distributed Systems, 15.

[13] Devi, B.U., Sundar, D. and Alli, P. (2013) An Effective Time Series Analysis for Stock Trend Prediction Using ARIMA Model for Nifty Midcap-50. International Journal of Data Mining \& Knowledge Management Process, 65-78. http://dx.doi.org/10.5121/ijdkp.2013.3106

[14] Chai, T. and Draxler, R.R. (2014) Root Mean Square Error (RMSE) or Mean Absolute Error (MAE)?-Arguments against Avoiding RMSE in the Literature. Copernicus Publications on Behalf of the European Geosciences Union.

[15] Fan, F., Bell, K. and Infield, D. (2016) Probabilistic Real-Time Thermal Rating Forecasting for Overhead Lines by Conditionally Heteroscedastic Auto-Regressive Models. IEEE Trans- 
actions on Power Delivery. http://dx.doi.org/10.1109/TPWRD.2016.2577140

[16] Fan, F., Bell, K. and Infield, D. (2016) Probabilistic Weather Forecasting for Dynamic Line Rating Studies. Proc. IEEE PowerTech Conference, 1-6.

http://dx.doi.org/10.1109/pscc.2016.7540854

\section{Submit or recommend next manuscript to SCIRP and we will provide best service} for you:

Accepting pre-submission inquiries through Email, Facebook, LinkedIn, Twitter, etc.

A wide selection of journals (inclusive of 9 subjects, more than 200 journals)

Providing 24-hour high-quality service

User-friendly online submission system

Fair and swift peer-review system

Efficient typesetting and proofreading procedure

Display of the result of downloads and visits, as well as the number of cited articles

Maximum dissemination of your research work

Submit your manuscript at: http://papersubmission.scirp.org/

Or contact wjet@scirp.org 